\section{FUMIFUNGIN, A NEW ANTIFUNGAL ANTIBIOTIC FROM ASPERGILLUS FUMIGATUS FRESENIUS 1863}

\author{
Triptikumar Mukhopadhyay, KiRity Roy, \\ LouIs COUTINHO, R. H. RuPP \\ and B. N. GANGULI
}

Research Centre, Hoechst India Ltd., Mulund, Bombay 400 080, India

\section{H. W. FehlHABeR}

\begin{abstract}
Pharmasynthese, Hoechst AG, Frankfurt a.M 80, Federal Republic of Germany
\end{abstract}

(Received for publication February 2, 1987)

From the metabolites present in the culture filtrate during the fermentation of a fungal culture, number Y-83,0405 and identified as Aspergillus fumigatus Fresenius 1863, a novel antifungal antibiotic, designated as fumifungin (1) was isolated. In this paper we report the isolation and structure elucidation of fumifungin.

The organism was isolated from a Himalayan soil sample. A few loopfuls of the well sporulated culture was used to inoculate $100 \mathrm{ml}$ of the seed culture medium (soluble starch $1.5 \%$, soybean meal $1.5 \%$, yeast extract $0.2 \%$, cornsteep liquor $0.1 \%$, glucose $0.5 \%, \mathrm{CaCO}_{3} 0.2 \%$, $\mathrm{NaCl} 0.5 \%$ in demineralized water at $\mathrm{pH} 6.5$ ) distributed in 500-ml Erlenmeyer flasks. The seed culture was grown on a rotary shaker $(240$ $\mathrm{rpm})$ at $26^{\circ} \mathrm{C}\left( \pm 1^{\circ} \mathrm{C}\right)$ for 60 hours.

After a good growth was obtained it was used to inoculate $(1 \%) 200 \mathrm{ml}$ of the production medium (glucose $1 \%$, malt extract $2 \%$, peptone $1 \%$, $\mathrm{Na}_{2} \mathrm{HPO}_{4} 0.1 \%, \mathrm{ZnSO}_{4} \cdot 7 \mathrm{H}_{2} \mathrm{O} 0.000022 \%, \mathrm{CaCl}_{2}$ $0.000055 \%, \mathrm{MnCl}_{2} \cdot 4 \mathrm{H}_{2} \mathrm{O} 0.00005 \%, \mathrm{FeSO}_{4} \cdot$ $5 \mathrm{H}_{2} \mathrm{O} \quad 0.000016 \%, \mathrm{CoCl}_{2} \cdot 6 \mathrm{H}_{2} \mathrm{O} \quad 0.000016 \%$ in demineralized water at $\mathrm{pH}$ 6.5) in 1-liter Erlenmeyer flasks. The fermentation was carried out on a rotary shaker $(220 \mathrm{rpm})$ at a temperature of $26^{\circ} \mathrm{C}\left( \pm 1^{\circ} \mathrm{C}\right)$ for 90 hours.

The culture filtrate (55 liters) at $\mathrm{pH} 5.9$ was percolated through a Diaion HP-20 (1.8 liters) column. The resin bed was washed with de- mineralized water ( 7 liters) followed by $50 \%$ aq $\mathrm{MeOH}$ (20 liters) and then eluted with $\mathrm{MeOH}$ $\mathrm{H}_{2} \mathrm{O}(4: 1)$ until no more activity could be detected in the eluates (10 liters). Concentrated active eluates ( 7 liters) were diluted with water (15 liters) and recharged on Diaion HP-20 (1 liter). The resin bed was washed with $60 \% \mathrm{MeOH}$ in water (10 liters) and then eluted with $\mathrm{MeOH}$ (4 liters). Removal of solvent gave crude fumifungin $(1.5 \mathrm{~g})$.

This crude material $(0.6 \mathrm{~g})$ was subjected to chromatography on reverse phase (octadecylsilyl) material $(50 \mu, 3.7 \times 40 \mathrm{~cm})$ at a flow rate of $11 \mathrm{ml} /$ minute. The column was eluted with $60 \%$ $\mathrm{MeOH}$ in water (1 liter) and then with $70 \%$ $\mathrm{MeOH}$ in water when fumifungin eluted out. The active fractions were concentrated under reduced pressure and then lyophilized to obtain pure fumifungin $(0.1 \mathrm{~g})$.

Fumifungin (1) is a colorless solid, $\mathrm{mp} 108^{\circ} \mathrm{C}$ soluble in DMSO, $\mathrm{MeOH}$ and aq $\mathrm{NaHCO}_{3}$. It decolorizes dilute $\mathrm{KMnO}_{4}$ solution and gives violet coloration with ninhydrin. Fumifungin has a molecular weight of 431 (fast atom bombardment mass spectrum (FAB-MS) $m / z \quad 432$ $\left(\mathrm{M}+\mathrm{H}^{+}\right)$) and molecular formula $\mathrm{C}_{22} \mathrm{H}_{41} \mathrm{NO}_{7}$ (high resolution electron impact mass spectra (HREI-MS) of the pertrimethylsilylated fumifungin: $\mathbf{M}^{\prime}=\mathrm{M}+5 \mathrm{TMS}, \mathrm{m} / \mathrm{z} 791.4860$, the fragmentation pattern is shown in Scheme 1). Elemental analysis obtained C 58.90, H 9.54, N

Scheme 1. Mass spectral fragmentation (HREI-MS) of pertrimethylsilylated fumifungin (1) showing structurally significant fragment ions.

$$
\mathrm{a}=m / z \quad 706.3879, \mathrm{~b}=m / z \quad 399.3119, \mathrm{c}=m / z
$$
392.1751, $\mathrm{d}=m / z \quad 674.4490, \mathrm{e}=m / z \quad 187.1520, \mathrm{f}=$ $m / z 573.3821, \mathrm{~g}=m / z 218.1035, \mathrm{R}=\mathrm{Si}\left(\mathrm{CH}_{3}\right)_{3}$.

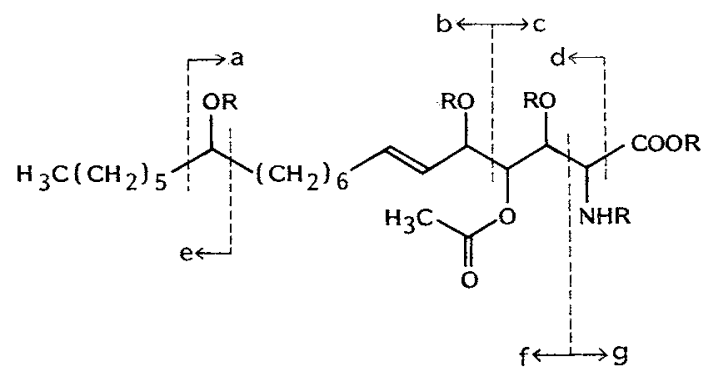


Fig. 1. IR spectrum (KBr, Perkin-Elmer 157) of fumifungin (1).

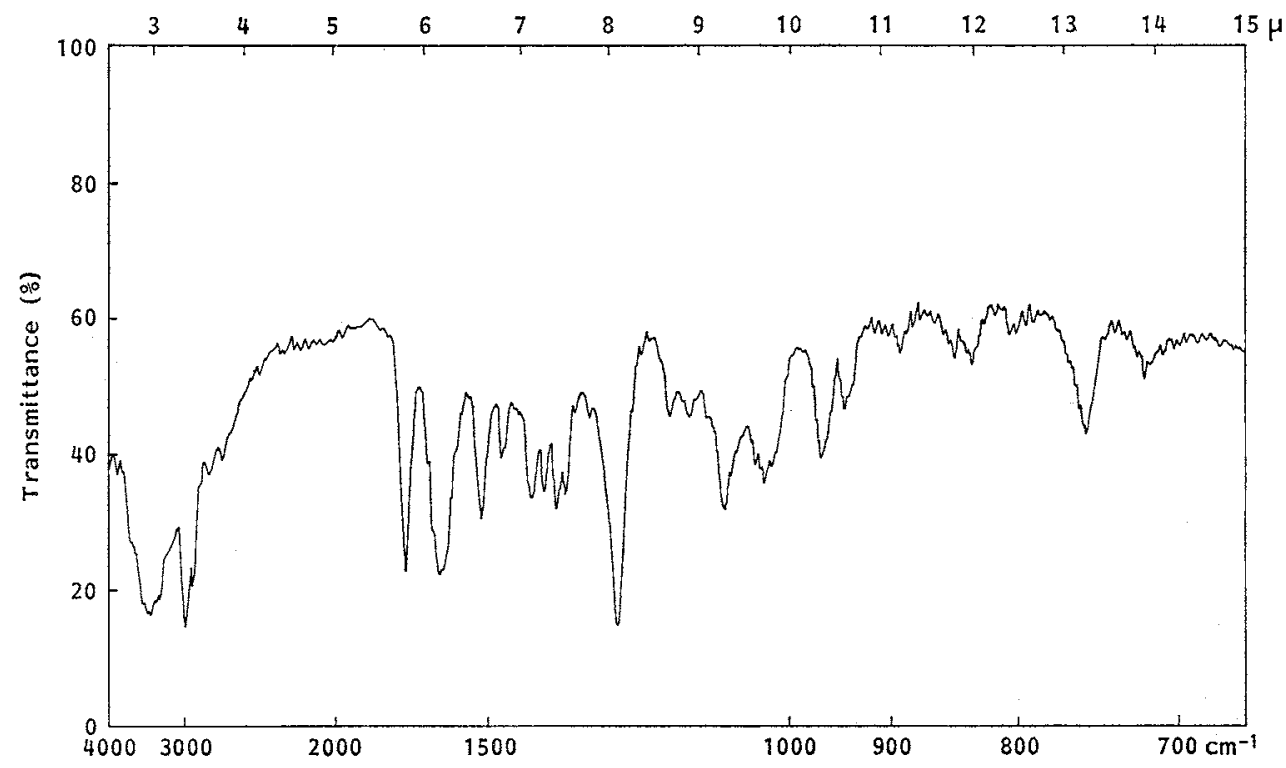

Fig. 2. $270 \mathrm{MHz}{ }^{1} \mathrm{H}$ NMR spectrum $\left(\mathrm{CD}_{3} \mathrm{OD}\right.$, Brucker $\left.\mathrm{AM}-270\right)$ of fumifungin (1); inset shows the $270 \mathrm{MHz}{ }^{1} \mathrm{H}$ NMR spectrum (DMSO- $d_{6}$ ) of the olefinic protons.

$5.80 \sim 5.95(1 \mathrm{H}, \mathrm{m}), 5.32 \sim 5.45(2 \mathrm{H}, \mathrm{m}), 4.16(1 \mathrm{H}, \mathrm{dd}, J=2$ and $4.5 \mathrm{~Hz}), 3.82(1 \mathrm{H}, \mathrm{d}, J=6 \mathrm{~Hz})$, $3.76(1 \mathrm{H}, \mathrm{d}, J=4.5 \mathrm{~Hz}), 3.50(1 \mathrm{H}, \mathrm{br} \mathrm{s}), 1.98 \sim 2.13(5 \mathrm{H}, \mathrm{s}$ and $\mathrm{m}$ overlapping $), 1.20 \sim 1.50(20 \mathrm{H}, \mathrm{m})$, $0.88(3 \mathrm{H}, \mathrm{t}, J=6 \mathrm{~Hz})$.

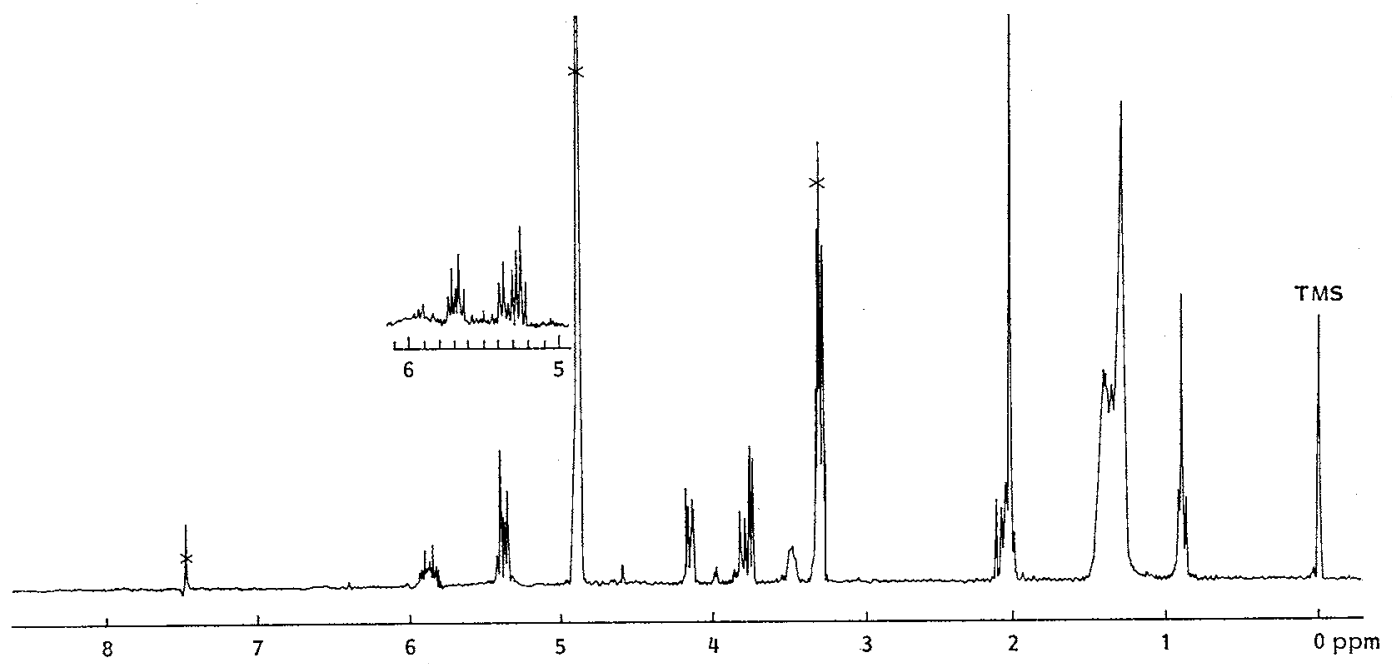

3.21 ; calcd for $\mathrm{C}_{22} \mathrm{H}_{41} \mathrm{NO}_{7}: \mathrm{C} 61.25, \mathrm{H} 9.51, \mathrm{~N}$ 3.20 .

Fumifungin does not have any characteristic UV absorption in $\mathrm{MeOH}$. Its IR and ${ }^{1} \mathrm{H}$ NMR spectra are shown in Figs. 1 and 2, respectively. The ${ }^{13} \mathrm{C}$ NMR spectrum (22.5 MHz, DMSO- $d_{8}$ ) showed the following signals: $\delta 169.37$ (s), 169.05 (s), 134.80 (d), 125.38 (d), 75.67 (d), 71.95 (d),
69.46 (d), 68.27 (d), 56.24 (d), 37.17, 31.64, $31.32,28.82,28.50,28.28,25.14,22.00,21.02$ and $13.76(\mathrm{q})$.

An analysis of all the data indicate that there are (a) two carbonyl groups - one carboxylic acid and an acetate, (b) a $-\mathrm{CH}_{2} \mathrm{CH} \stackrel{E}{=} \mathrm{CHCH}-$ group, (c) a - $\mathrm{CHCH}(\mathrm{O}-) \mathrm{CH}-$ group, (d) a total of four $\mathrm{CH}-\mathrm{O}$ groups and one $\mathrm{CH}-\mathrm{N}$ group, (e) 
<smiles>CCCCCCCCCCCCCCCCCCCCCCCCCCCCCC(=O)O</smiles>

1

Table 1. Antifungal activity of fumifungin (1).

\begin{tabular}{lc}
\hline \multicolumn{1}{c}{ Microorganism } & $\begin{array}{c}\text { MIC } \\
\text { values } \\
(\mu \mathrm{g} / \mathrm{ml})\end{array}$ \\
\hline Candida albicans & 62.5 \\
Saccharomyces cerevisiae & 62.5 \\
Wild yeast & 62.5 \\
Aspergillus niger & 7.8 \\
Penicillium digitatum & 7.8 \\
Trichophyton mentagrophytes & 15.6 \\
Botrytis cinerea & 150 \\
Fusarium culmorum & 250 \\
Alternaria solani & 31.2 \\
Cercospora beticola & 0.9 \\
Cladosporium resinae & 0.9 \\
Piricularia oryzae & 125 \\
\hline
\end{tabular}

a $\mathrm{CH}_{2} \mathrm{CH}_{3}$ group and (f) about ten $\mathrm{CH}_{2}$ groups present in fumifungin. Interpretation of the high resolution mass spectral fragmentation as shown in Scheme 1 established the structure of fumifungin as 2-amino-4-acetoxy-3,5,14-trihydroxy- $\Delta^{3}$-eicosenoic acid. As can be seen from the structure 1, fumifungin is a long chain amino acid and is similar to thermozymocidin ${ }^{1 /} /$ myr- $^{2}$ iocin $^{2 \sim 4)}$ in its chemical structure. Stereochemistry of the chiral centers of fumifungin have not been determined.

From the culture filtrate a known antibacterial antibiotic, SC-28762/viriditoxin (2) ${ }^{5}$, has also been isolated.<smiles>[Z]C([Z])(C)C1=C(O)C2=C(O)C3=C(CC(CC(=O)OC)OC2=O)C(=C1OC)CCC3</smiles>

2

MIC values of fumifungin (1) against some selected fungi are shown in Table 1.

Acknowledgments

We would like to thank Mrs. N. BHAT for her technical assistance and Dr. P.K. INAMDAR for providing us with the elemental analysis and some spectra.

\section{References}

1) Aragozzini, F.; P. L. Manachini, R. Craveri, B. Rindone \& C. SCOLASTICO: Isolation and structure determination of a new antifungal $\alpha$-hydroxymethyl- $\alpha$-amino acid. Tetrahedron 28: 5493 5498, 1972

2) Kluepfel, D.; J. Bagli, H. Baker, M.-P. Charest, A. Kudelski, S. N. Sehgal \& C. VÉZINA: Myriocin, a new antifungal antibiotic from Myriococcum albomyces. J. Antibiotics 25: 109 115, 1972

3) BaGi, J. F.; D. Kluepfel \& St. J. Maurice: Elucidation of structure and stereochemistry of myriocin. Novel antifungal antibiotic. J. Org. Chem. 38: 1253 1260, 1973

4) Payette, D. R. \& G. Just: A total synthesis of the enantiomer of anhydromyriocin (anhydrothermozymocidin). Can. J. Chem. 59: 269 282, 1981

5) JiU, J. \& S. Mizuba: Metabolic products from Spicaria divaricata NRRL 5771. J. Antibiotics 27: $760 \sim 765,1974$ 